\title{
THREE-DIMENSIONAL COMPUTATIONAL FLUID DYNAMICS FOR THE SPALLATION NEUTRON SOURCE LIQUID MERCURY TARGET ${ }^{a}$
}

\author{
Mark W. Wendel \\ Computational Physics \& Engineering Division \\ Oak Ridge National Laboratory \\ P. O. Box 2008 \\ Bldg. 6011, MS-6415 \\ Oak Ridge, Tennessee, 37831-6415, USA \\ Tel: 423-574-2825, Fax: 423-576-0003 \\ email: mwq@ornl.gov
}

\author{
Moshe Siman-Tov \\ AUG 13 1998 \\ Engineering Technology Division
Oak Ridge National Laboratory \\ P. O. Box 2008 \\ Bldg. 9204-1, MS-8045 \\ Oak Ridge, Tennessee, 37831-8045 \\ Tel: 423-574-6515, Fax: 423-574-2032 \\ email: mst@ornl.gov
}

\section{ABSTRACT}

The Spallation Neutron Source (SNS) is a high-power accelerator-based pulsed spallation source being designed by a multilaboratory team led by Oak Ridge National Laboratory (ORNL) to achieve high fluxes of neutrons for scientific experiments. Computational fluid dynamics (CFD) is being used to analyze the SNS design. The liquid-mercury target is subjected to the neutronic (internal) heat generation that results from the proton collisions with the mercury nuclei. The liquid mercury simultaneously serves as the neutronic target medium, transports away the heat generated within itself, and cools the metallic target structure. Recirculation and stagnation zones within the target are of particular concern because of the likelihood that they will result in local hot spots. These zones exist because the most feasible target designs include a complete $U$-turn flow redirection. Although the primary concern is that the target is adequately cooled, the pressure drop from inlet to outlet must also be considered because pressure drop directly affects structural loading and required pumping power. Based on the current design, a three-dimensional CFD model has been developed that includes the stainless steel target structure, the liquid-mercury target flow, and the liquid-mercury cooling jacket that wraps around the nose of the target.

\section{INTRODUCTION}

The Spallation Neutron Source (SNS) is a high-power accelerator-based pulsed spallation source being designed by a multilaboratory team led by Oak Ridge National Laboratory
(ORNL) to achieve high fluxes of neutrons for scientific experiments. ${ }^{1}$ The SNS is projected to have a 1-MW proton beam that is upgradable to $5 \mathrm{MW}$ with an elliptical beam cross section of $7 \times 20 \mathrm{~cm}$. About $60 \%$ of the beam power is deposited in the liquid-metal (mercury) target ${ }^{2}$ having the dimensions of $65 \times 40 \times 10 \mathrm{~cm}$ (about $20 \mathrm{~L}$ ). Figure 1 shows the schematic for the target design as of January 1998. The target is subjected to the neutronic (internal) heat generation that results from the proton collisions with the mercury nuclei. Peak instantaneous power density is as high as 23,000 $\mathrm{GW} / \mathrm{m}^{3}$, or $23 \times 10^{6} \mathrm{MW} / \mathrm{m}^{3}$, for the 1-MW beam. The peak pulse rate of temperature rise is $13 \times 10^{6} \mathrm{~K} / \mathrm{s}$ (for $1-\mathrm{MW}$ beam), whereas the total pulse temperature rise is less than 6 $\mathrm{K}$. The distribution of power deposition within the mercury has a peak-to-average ratio of about 7 axially and 2.0 radially. The target stainless steel has a similar spatial distribution of heat. In addition to thermal shock and materials compatibility, key feasibility issues for the target are related to its thermal-hydraulic performance.

The liquid mercury simultaneously serves as the neutronic target medium, transports away the heat deposited within itself, and cools the metallic target structure. The proton beam (see Fig. 1) is parallel to the predominant direction of flow. The beam first passes through the stainless steel window on the front of the target, which is provided with supplemental exterior cooling by an attached cooling jacket that wraps around the target lengthwise. The transverse extent of the cooling jacket is limited to the width necessary to contain the proton beam footprint. Recirculation and stagnation zones within the target are of particular interest

\footnotetext{
${ }^{2}$ The submitted manuscript has been authored by a contractor of the U.S. Government No. DE-AC05-960R22464. Accordingly, the U.S. Govemment retains a nonexclusive, royalty-free license to publish or reproduce the published form of this contribution, or allow others to do so, for U.S. Government purposes.

'Oak Ridge National Laboratory is managed by the Lockheed Martin Energy Research Corp. for the U.S. Department of Energy under Contract No. DE-AC05-96OR22464.
} 
DISCLAIMER

This report was prepared as an account of work sponsored by an agency of the United States Government. Neither the United States Government nor any agency thereof, nor any of their employees, makes any warranty, express or implied, or assumes any legal liability or responsibility for the accuracy, completeness, or usefulness of any information, apparatus, product, or process disclosed, or represents that its use would not infringe privately owned rights. Reference herein to any specific commercial product, process, or service by trade name, trademark, manufacturer, or otherwise does not necessarily constitute or imply its endorsement, recommendation, or favoring by the United States Government or any agency thereof. The views and opinions of authors expressed herein do not necessarily state or reflect those of the United States Government or any agency thereof. 


\section{DISCLAIMER}

Portions of this document may be illegible in electronic image products. Images are produced from the best available original document. 
because of the likelihood that they will result in local hot spots. Such zones occur in the most feasible target designs, which include a U-turn flow redirection. Due to the complicated flow path followed by the liquid mercury, it is necessary to ensure that the temperatures and thermal gradients remain acceptably low in the mercury itself, as well as in the stainless steel target structure. The target pressure drop must also be considered because it directly affects structural loading and required pumping power.

Computational fluid dynamics (CFD) is being used to assist in the design of the SNS target by providing flow visualization and quantifying critical parameters. The simplest approach to the fluid dynamics analysis is to timeaverage the problem. This averaging is accomplished by spreading the pulse energy evenly throughout the entire period of $0.01667 \mathrm{~s}$ (corresponding to a pulse frequency of 60 cps), thus allowing the simulation to be performed as a steady state. An additional level of averaging is assumed in order to apply the Reynolds-averaged two-equation turbulence model. The steady-state solution should provide a reasonable estimate for the overall flow pattern and temperature distribution within the target enclosure. Also of concern, however, are transient effects which occur on the microsecond time scale and which impact the target performance. These effects include small spatial and temporal variations in the flow field and pressure waves induced by rapid thermal expansion (density decrease) of the heated liquid. This CFD model is useful for looking at compressibility effects such as the pressure waves, however, the fluid/structure interaction at the wall, which is crucial, cannot be represented without additional model development. A separate study is under way ${ }^{3}$ to quantify the pressure wave amplitudes including fluid/structure interaction.

Two-dimensional simulations were previously $y^{4}$ completed including actual target simulations for various design configurations. The cooling jacket central channel was also modeled separately and in three dimensions. Because it was modeled separately, the thermal connection to the main target flow was performed manually through the use of heat transfer coefficients. Also, studies have been completed to validate predictions of the turbulent heat transfer and irreversible pressure loss.

The model from which the present results were produced is a full three-dimensional (3-D) representation of the liquid mercury and stainless steel structure, including all of the cooling jacket channels without the need for heat transfer coefficients.

\section{PREVIOUS WORK}

Previously, the simulations were either two-dimensional (2D) or a simple extruded 3-D geometry that did not accurately represent important 3-D aspects of the target design. ${ }^{4}$ The two-dimensional geometry was taken from the horizontal cross-section passing through the centerline of the target. The correct (within 3\%) cross-sectional flow area was applied to both channels by specifying a channel depth of $0.0823 \mathrm{~m}$. Hence, the average flow velocity computed was within $3 \%$ of the actual value in both the central rectangular and the peripheral semicircular channels.

Evaluation of the model was performed to assess both numerical and physical accuracy. The numerical uncertainty resulting from the finite volume discretization was investigated by repeating one of the cases with a refined mesh (having four times the number of nodes.) The computed flow field was shown to be insensitive to the grid refinement, hence the solution on the original mesh represents an accurate solution of the difference equations.

Comparisons of CFD heat transfer results with relevant experimental data and theory have been performed. ${ }^{4}$ For forced convection to liquid metal in a straight cylindrical pipe, the CFD model predicted Nusselt numbers $19-40 \%$ higher than the published theoretical values. This information can be used to supply turbulent Prandtl numbers for the SNS target simulations.

Also, a comparison with data has been completed for irreversible pressure loss. ${ }^{4}$ When compared with published experimental form-loss coefficients, the pressure drop predicted by the CFD was in excellent agreement with the measured data for the flow configuration used in the SNS target (i.e. flow entering in the side channels and exiting through the center channel).

\section{DESCRIPTION OF THE MODEL}

The general-purpose CFD code CFX, ${ }^{5}$ which uses a finitevolume, pressure-correction method, is being used to simulate the incompressible, temperature and velocity distribution in the liquid-mercury target. The model includes solid conducting regions that represent the stainless steel target walls and internal baffle. Heat generation is modeled in both of these regions. A renormalization-group (RNG) isotropic, two-equation turbulence model provided by CFX is used in combination with the standard law-of-the-wall boundary condition for imposing wall heat fluxes in the energy equation and shear stress in the momentum equations.

The boundary conditions include no-slip at the walls (simulated by turbulence wall functions), specified velocity at the primary inlet and cooling-jacket inlets, and specified pressure at the outlet boundaries. The density was assumed to be constant, but the viscosity and thermal conductivity were allowed to vary with temperature. The temperature variations were included only for consideration in the law-of- 
the-wall formulation (outside the boundary layer, the eddy viscosity dominates); however, the variation had very little significance in the results. With a liquid metal such as mercury, the temperature gradient (and corresponding property variation) near the wall is much less severe because of high thermal conductivity.

The discretization used for the current model includes 717,000 computational cells and is shown in Figs. 2 and 3. Only one-half of the target is modeled due to symmetry. Although the main flow through the target has an additional (horizontal) plane of symmetry, the cooling-jacket flow is not symmetric about this plane since it flows from the bottom to the top. Figure 2 shows the outside surface of the computational domain (corresponding to the outside surface of the stainless steel structure.) Figure 3 shows the computational grid represented by a few horizontal and vertical slices through the domain. Computational cell dimensions vary from $0.001 \mathrm{~m}$ near the tip of the flow baffle up to $0.100 \mathrm{~m}$ in the streamwise direction near the inlet-outlet plane. The grid was carefully selected to keep transitions in grid size smooth and to place the near-wall nodes at a distance from the wall that would satisfy the requirement of the turbulent law-of-the-wall condition. This requirement is that the node next to the wall must be located within the inner layer, but not in the laminar sublayer $\left(11<\mathrm{y}^{+}<50\right)$.

The large number of computational cells required all of the $512 \mathrm{MB}$ of RAM available on the computing platform. To get the appropriate level of discretization an "unmatched grid surface" was specified in the cooling jacket mercury volume. This option in the CFX computer program allows for an abrupt change in grid stucture across a specified surface. Using this capability, a fine grid was applied through the cooling jacket thickness for the central subchannel, and a coarser grid was used in the outer three subchannels. The central channel lies across the center of the beam path, and therefore is relied upon more than the other channels for cooling. Without the unmatched grid option, it would have been necessary to refine all of the cooling channels, and the problem would have been intractable unless more computer memory had been obtained.

The effect of the inlet/outlet transition piece, shown in Fig. 1 , on the flow near the nose of the target is neglected since its design is not yet complete. Future analysis will incorporate that part as well.

\section{SIMULATION RESULTS}

The assumptions include an inlet temperature of $353 \mathrm{~K}$ and a total target heat loading of $0.6 \mathrm{MW}$, corresponding to the 1MW proton beam. An elliptic beam cross section is assumed with a parabolic power distribution, as shown in the elevated plot for the horizontal midplane in Fig. 4. This heat- generation assumption represents a curve fit to Monte Carlo neutronics calculations. ${ }^{2}$ Because the neutronics calculations used a very coarse grid, a 3-D curve fit was applied in piecewise fashion to fit the computed data. Discontinuities in the heat generation (e.g., Fig. 4) occur only at material boundaries where the liquid $\mathrm{Hg}$ contacts stainless steel. The mass flow rate was assumed to be $146 \mathrm{~kg} / \mathrm{s}$, corresponding to an average center-channel velocity of $0.57 \mathrm{~m} / \mathrm{s}$ and an average side-channel velocity of $0.76 \mathrm{~m} / \mathrm{s}$.

Steady-state convergence from a zero initial condition required a few days of CPU time on an IBM RS6000 Model 590 Workstation. A level of convergence was obtained such that the cumulative mass conservation error was less than $0.2 \%$ of the total target mass flow rate. The CFX algebraic multigrid (AMG) linear solver greatly enhanced the rate of convergence.

Temperature and speed contours on two cross sections show a large recirculation zone downstream of the flow baffle around which the liquid mercury makes the U-turn (Fig. 5). This large zone obstructs about one-half of the cross-sectional area in the central rectangular channel. Two smaller stagnation zones are also predicted in the corner of the target volume and near the stagnation point on the centerline. The recirculating flow causes a relatively high pressure drop $(9.1 \mathrm{kPa})$ through the target in addition to elevating the local temperatures because of the high local residence time of the fluid. The problem is compounded because the location of the large recirculation zone lies directly inside the beam path, where the rate of neutronic heating is high.

Figure 6 shows the vertical cross section at $z=0.4425 \mathrm{~m}$, the point where the maximum temperature in the recirculation zone is predicted. The swirling component of the flow can be clearly seen from the indicated flow lines which represent only velocity components in the plane of the paper. The peak temperature in the recirculation zone $\left(151.1^{\circ} \mathrm{C}\right)$ is located slightly above center due to the effect of the cooling jacket.

The vertical flow component is large in all three of the recirculation zones. This is illustrated in Fig.7, which shows some slices through the target and some 3-D streamlines. The streamlines were all calculated with seed points located in the inlet side channel and slightly above the horizontal midplane $(y=0)$. However, when the lines enter a recirculation zone they rise rather markedly in the vertical direction, indicating the 3-D nature of the recirculation zones.

Two significant peaks exist in the liquid-mercury steadystate target temperature distribution. The first is located in the large recirculation zone, where the fluid residence time is high (low speed) but the heat generation is only $187 \mathrm{MW} / \mathrm{m}^{3}$ ( $27 \%$ of the maximum heat generation). The second (and highest) peak is located at the front of the target near the 
proton beam window. This second peak is also in a recirculation zone and a region of low speed. The peak temperatures, both in the large recirculation zone and near the beam window, are given in Table 1 . The very front of the target window is located at $z=0.55 \mathrm{~m}$. The $x$ and $y$ coordinates are both measured from the beam centerline. The maximum stainless steel temperatures are $138^{\circ} \mathrm{C}$ in the flow baffle near the large recirculation zone, and $150^{\circ} \mathrm{C}$ in the stainless steel beam window.

The locations of the peak temperatures are elevated (at higher $y$ values) because of the influence of the cooling jacket. Cold mercury flows in along the bottom of the jacket, heats up as it cools the beam window, and then flows back hot along the top of the jacket. Also, as shown in Fig. 8, the peak temperature near the window is offset by about $2 \mathrm{~cm}$ in the lateral direction from the centerline, even though the heat generation is the highest on the centerline. This bias is due to the recirculation pattern in the main target flow near the beam window and centerline.

Liquid mercury enters the cooling jacket through seven subchannels (three and one-half of which are modeled due to symmetry). The geometry of the cooling jacket is symmetrical to about the horizontal midplane; however, the flow comes in at the bottom and exits out at the top. The ribs that separate the cooling channels exist only on the top and bottom of the target. At the nose, all of the cooling jacket mercury flows together in a common plenum region that gradually narrows in thickness from $3 \mathrm{~mm}$ down to $1 \mathrm{~mm}$ at the horizontal midplane. The computed flow field in the cooling jacket is illustrated in Fig. 9, where some of the steel is not shown and a surface passing midway through the cooling-jacket channel is shaded based on speed and temperature. Here, the effect of the ribs is clear. The cooling is most effective between the ribs, where the speed is higher and the temperature lower. As the thickness of the cooling-jacket channel narrows at the nose, a peak speed of $2.5 \mathrm{~m} / \mathrm{s}$ is reached.

Table 1. Peak mercury temperatures predicted by 3-D CFD target model.

\begin{tabular}{l|c|c|c|c} 
Location & $\begin{array}{c}\text { Peak } \\
\text { Temp. } \\
\left({ }^{\circ} \mathrm{C}\right)\end{array}$ & $\begin{array}{c}x \\
(\mathrm{~m})\end{array}$ & $\begin{array}{c}y \\
(\mathrm{~m})\end{array}$ & $\begin{array}{c}z \\
(\mathrm{~m})\end{array}$ \\
\hline \hline $\begin{array}{l}\text { Large } \\
\text { recirc. } \\
\text { zone }\end{array}$ & 151 & 0.064 & 0.006 & 0.443 \\
$\begin{array}{l}\text { Near } \\
\text { window }\end{array}$ & 166 & 0.023 & 0.005 & 0.543
\end{tabular}

\section{CONCLUSIONS}

The predicted thermal-hydraulic performance of the SNS target for 1-MW operation has been presented based on 3-D CFD calculations. The working limit of the target due to material considerations is $200^{\circ} \mathrm{C}$. At these conditions, the target temperatures are acceptably low (peak temperature of $\left.165^{\circ} \mathrm{C}\right)$.

There will be some increase in predicted temperature once the turbulence model has been calibrated based on the forced-convection validation results, but it is not likely to be as much as $35^{\circ} \mathrm{C}$, which is the current predicted margin.

The total pressure drop through the target is $9.1 \mathrm{kPa}$, which is within $1 \%$ of that predicted by previous $2-\mathrm{D}$ calculations.

Three recirculation zones in the steady-state flow pattern have been quantified: the largest next to and downstream of the baffle, one at the beam centerline near the window, and one in the quarter-sphere target corner outside the beam. The flow in all three of these zones is highly 3-D. The first two of these recirculation zones result in elevated temperatures because they lie in the beam path. The third recirculation zone is located in a region of virtually zero heat generation and is therefore inconsequential.

Because of the large variations in speed within the beam path, the peak temperatures are strongly dependent on beam power distribution. Therefore, parametric studies are planned that investigate the sensitivity of the peak temperatures and temperature gradients to beam alignment and characterization. It is also still important to determine how much effect the inlet transition piece has on the flow distribution. This determination can be made by improving the model to include the piece, or some simpler sensitivity studies can be performed that significantly alter the inlet geometry, looking for changes in the flow pattern near the nose.

\section{NOMENCLATURE}

$x$ horizontal space coordinate parallel to $\mathbf{m}$ proton beam

$y$ horizontal coordinate perpendicular to $\mathrm{m}$ proton beam

$y^{+} \quad$ wall coordinate in law-of-the-wall boundary condition (dimensionless) 


\section{ACKNOWLEDGMENTS}

The authors would like to acknowledge the staff at AEA Technology Engineering Software, Inc., for their strong technical support in applying the CFX program to the problem of interest.

\section{REFERENCES}

1. M. Siman-Tov, et al. "Thermal-Hydraulic Analysis of the Liquid Mercury Target for the National Spallation Neutron Source," Proc. Int. Topical Meeting on Advanced Reactor Safety (ARS '97), Orlando, Florida, June 1-5, 1997.

2. T. A. Gabriel et al., "Overview of the SNS Target Station," Proc. Int Topical Mtg. Advanced Reactor Safety (ARS '97), Orlando, Florida, June 1-5, 1997.

3. R. P. Taleyarkhan et al., "Results of Thermal Shock Modeling and Analyses for the National Spallation Neutron Source," Proc. Topical Mtg. Nuclear Applications of Accelerator Technology, Albuquerque, New Mexico, November 16-20, 1997, p. 293.

4. M. W. Wendel, M. Siman-Tov, "CFD Analysis of a Liquid Mercury Target fo the National Spallation Neutron Source," Proc. ASME Fluids Engineering Division Summer Mtg., June 22-26, 1997.

5. CFX-4.2: SOLVER, User's Manual, AEA Technology, CFX International, Oxfordshire, United Kingdom, December 1997.

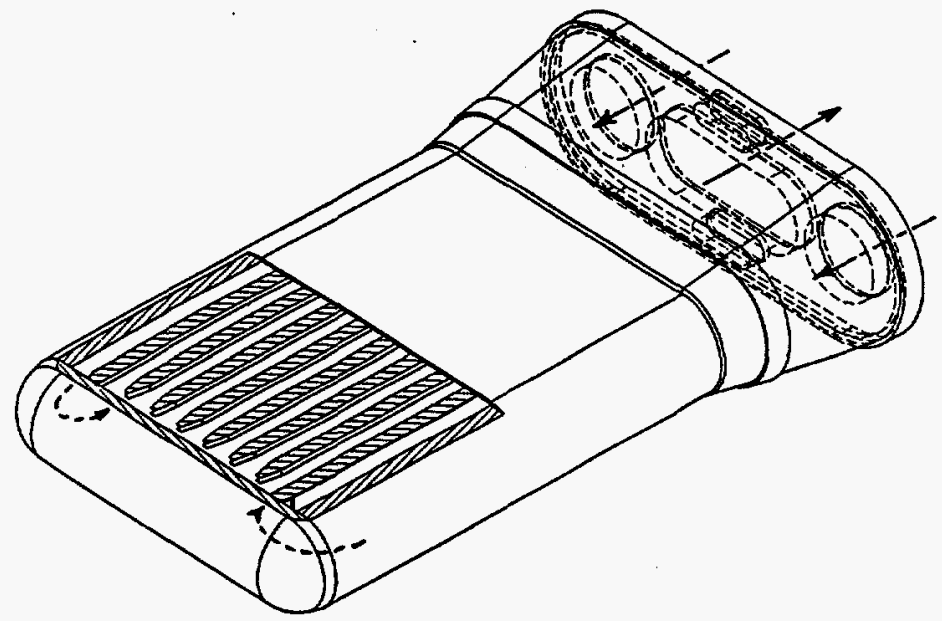

Fig. 1. Design schematic showing the SNS stainless steel target enclosure used for liquid mercury containment.

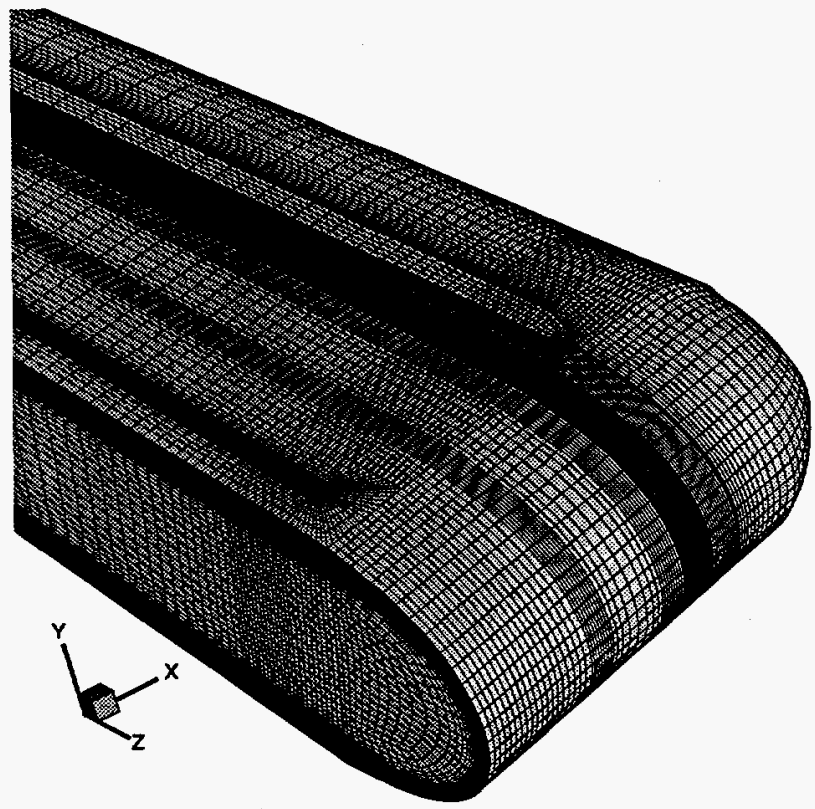

Fig. 2. Discretization of target domain: external view.

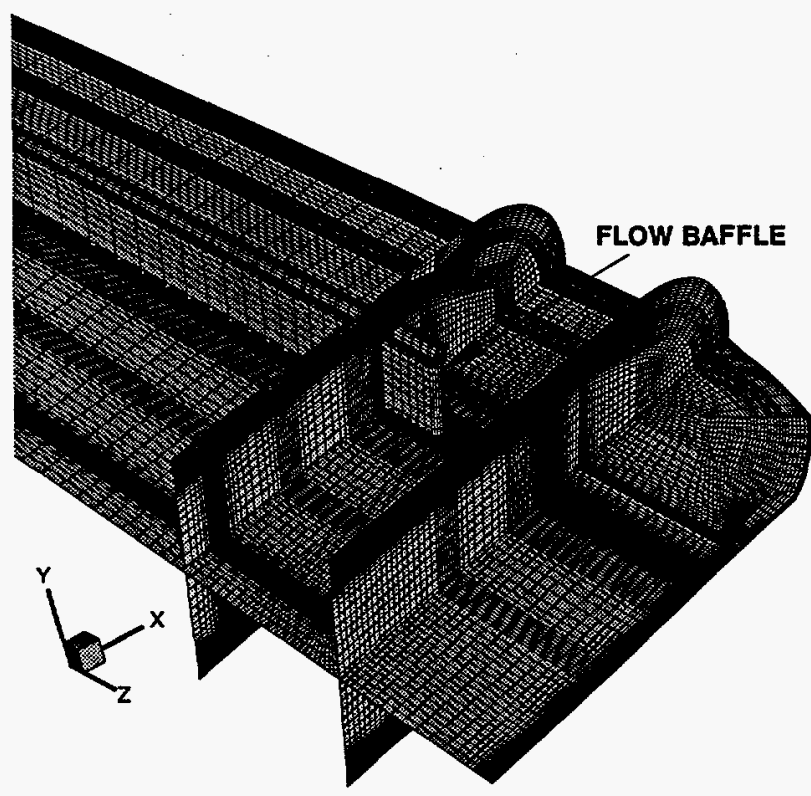

Fig. 3. Discretization of target domain: internal view. 


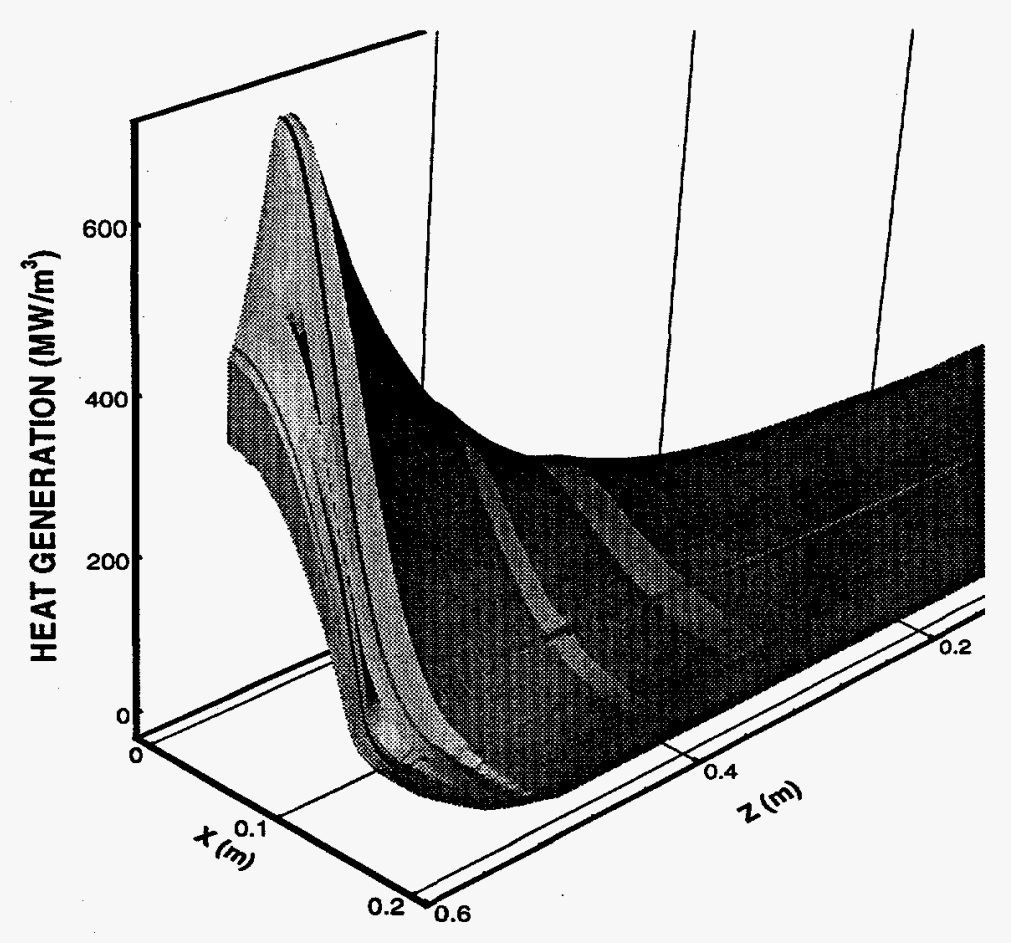

Fig. 4. Heat generation across horizontal midplane.
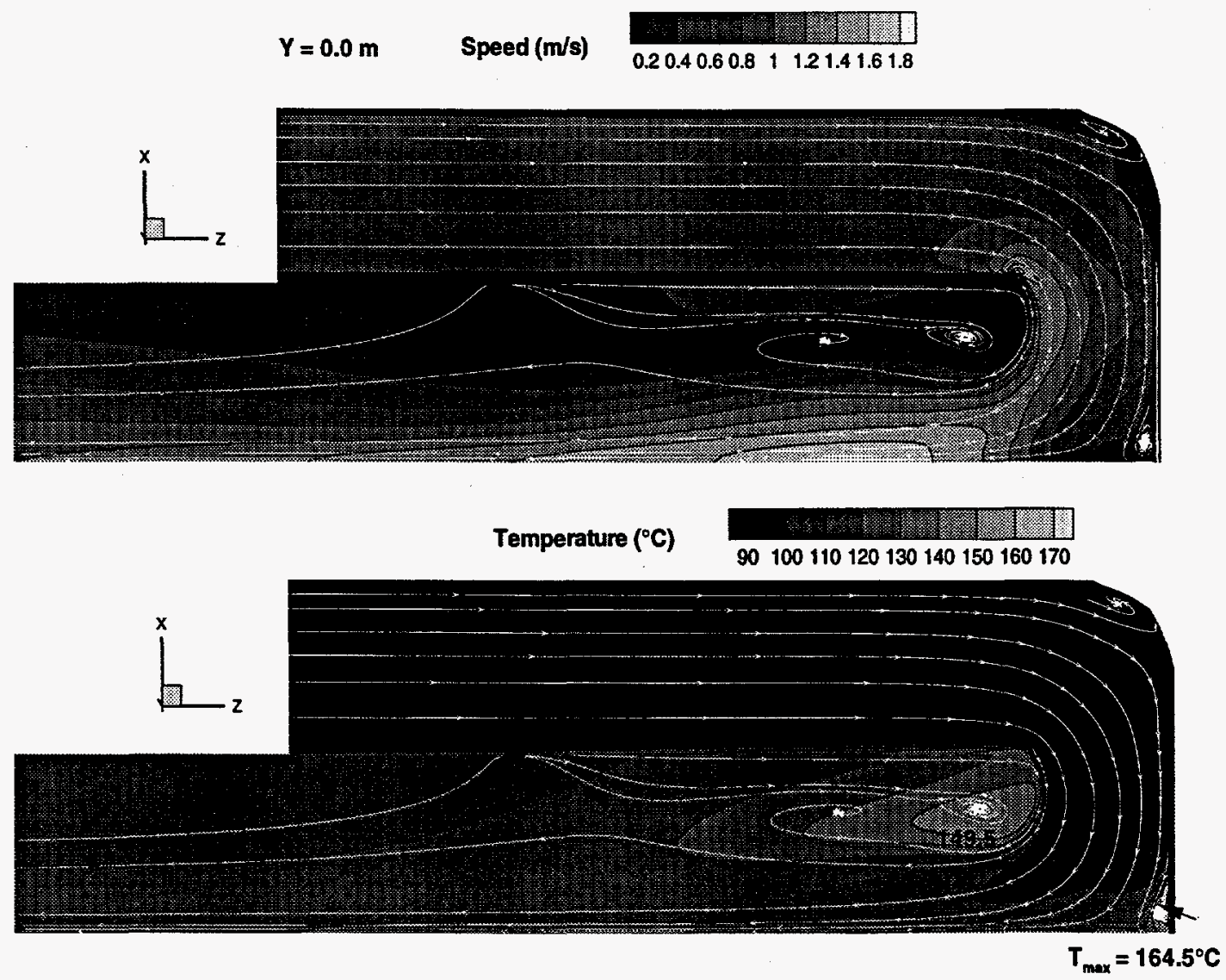

Fig. 5. Contours for speed and temperatures on horizontal midplane $(y=0)$. 


\section{$Z=0.4425 \mathrm{~m}$ \\ (plane of $\mathrm{T}_{\max }$ in recircirculation zone)}
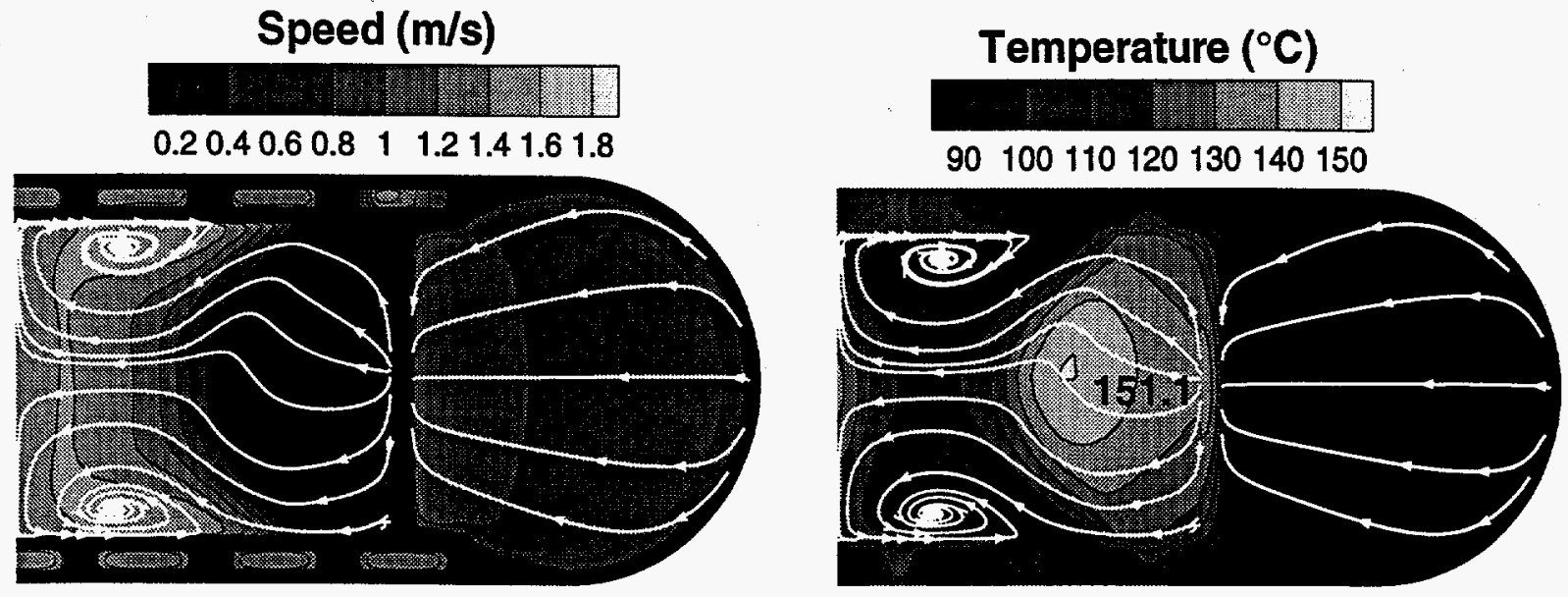

Fig. 6. Contours for speed and temperature on the vertical cross-section passing through the peak temperature in the recirculation zone.

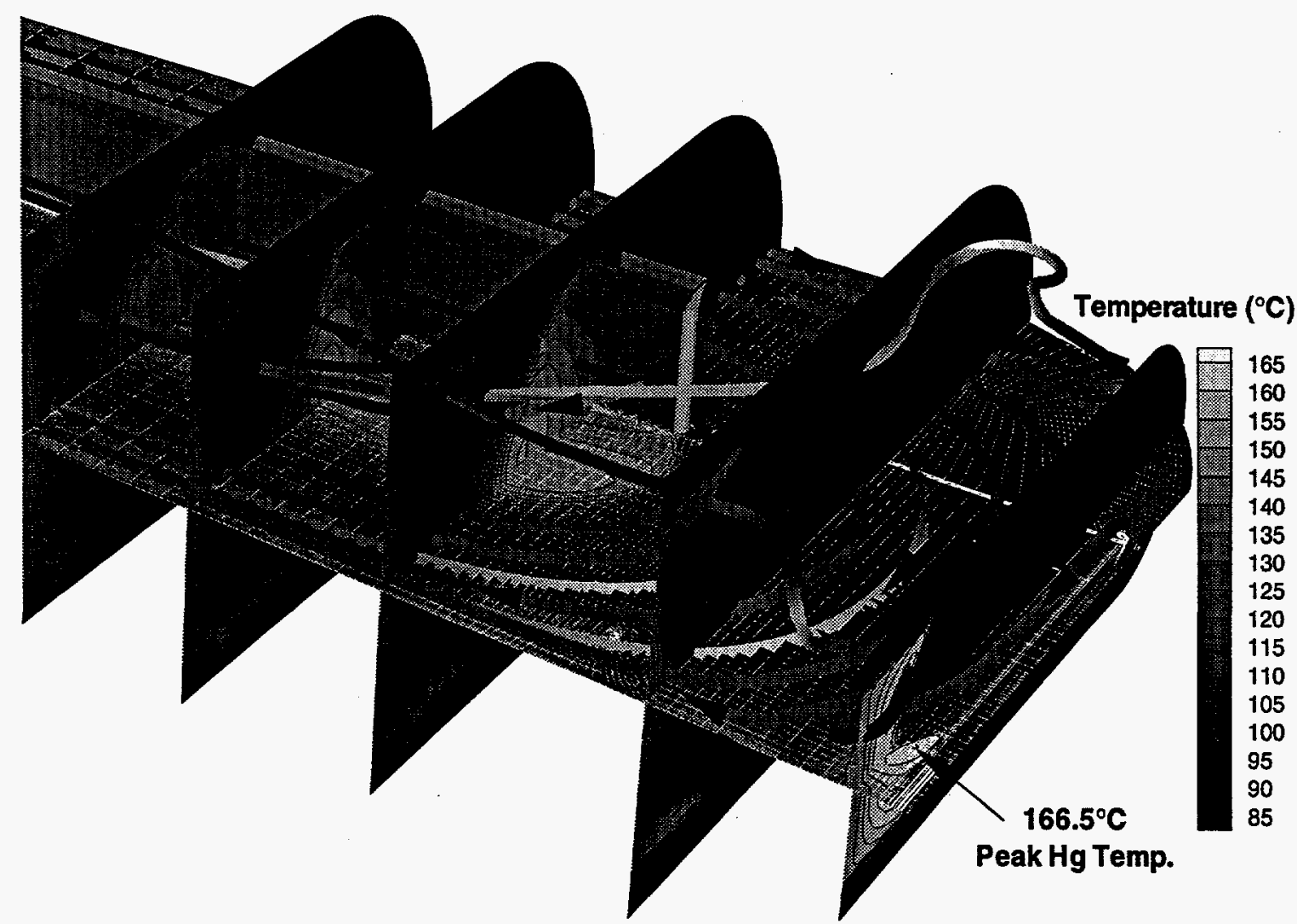

Fig. 7. Slices through target computational domain showing temperature contours and threedimensional stream lines. 


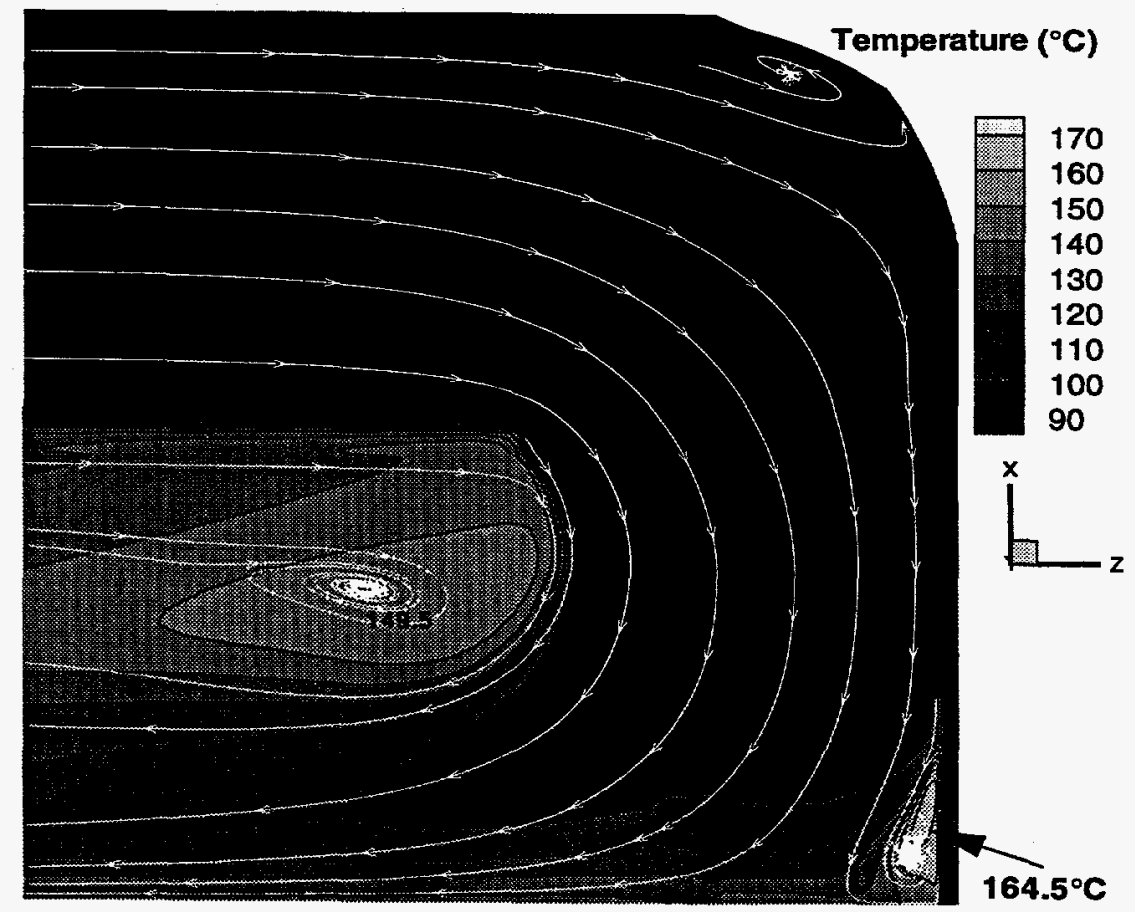

Fig. 8. Closup of horizontal midplane near stainless steel window.
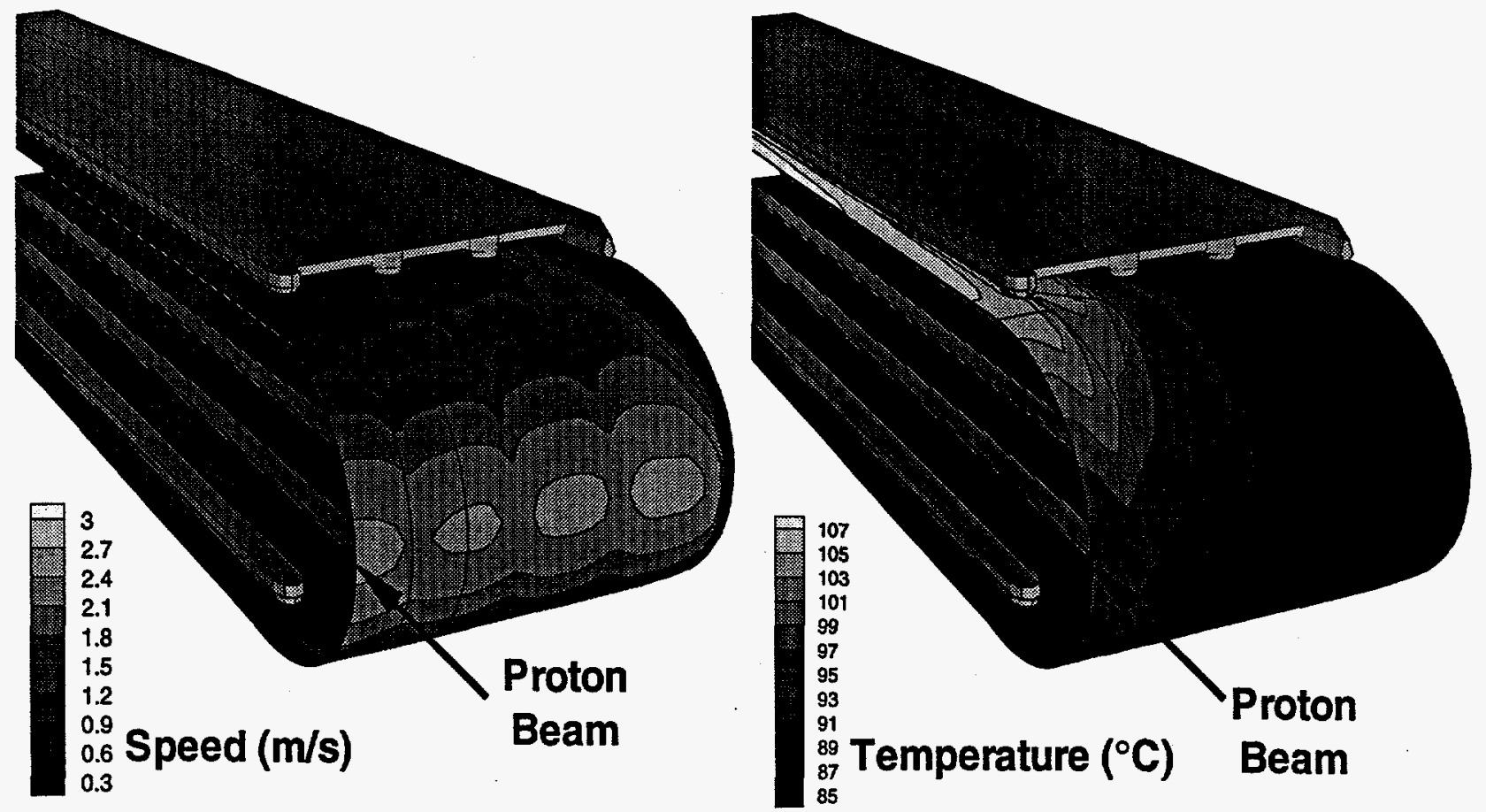

Fig. 9. Cooling jacket speed and temperature. 